\title{
An Analysis on the Morphological Relationship of Hair Styles with Changes in Necklines and Collars: \\ From 16th Century to 19th Century
}

\author{
Kim Hyoju • Bae Soojeong ${ }^{+}$ \\ Dept. of Clothing \& Textiles, Chonnam National University \\ Dept. of Clothing and Textiles, Chonnam National University, Human Ecology Research \\ Institute, Chonnam National University
}

\begin{abstract}
This thesis aims to investigate the morphologic relationship among the neckline, collar, and hair style, in which the width and height were measured by selecting the representative costumes from 16th to 19th centuries. The pieces of 170 pictures selected by fashion experts were cut in the same condition, with the part of the end of shoulder, head, and chest all placed on the equal level. The products were directly measured by a team of 3 specialists for verification of this study, of which results were calculated into average. The values of output were categorized into the unit of decade and finally into a graph of variation, in which the trend and relationship were evaluated according to the width and height. In 16th century, the width and height of the neckline were inversely proportional to those of hair style, while those of collar were proportional to those of hair style. In 17th century, the width and height of the hair style were proportional to those of neckline and collar. In 18th century, those of the neckline were inversely proportional to the hair style, with no collar found. In 19th century, the width of the neckline and collar were proportional to that of the hair style, while the height of the neckline and collar were inversely proportional to that of the hair style. The analysis of the morphologic relationship among neckline, collar, and hair style resulting from this study revealed that the change of the hair style took place corresponding to those of neckline and collar. Generally, the width of the hair style was found to be more resistant to change, compared to those of neckline and collar that were more susceptible. The height of the neckline was more resistant to change, compared to those of the hair style and collar presenting their frequently fluctuating height. Conclusively, the factor of height rather than that of width showed more dominant proportions, because the various forms of the collar and hair style evolved in terms of the height rather that width, relative to that of the neckline.
\end{abstract}

Corresponding author: Bae Soojeong, Tel. +82-62-530-1344, Fax. +82-62-530-1349

E-mail : sjbae@chonnam.ac.kr

This research is a part of master's thesis.

This research was presented at the 2014 Spring Conference of The Korean Society of Fashion Business. This research was supported in 2014 by the MOE (The Ministry of Education), Republic of Korea, under the BK21 plus project (S13HR15D0801) supervised by the NRF (National Research Foundation of Korea). 
Journal of Fashion Business Vol.18, No.3

Key words : collar, fashion coordination, hair style, morphological relationship, neckline

\section{Introduction}

The beauty to modern women is not only just grooming and decorating anymore but also the unspoken means to represent themselves. Aesthetic to human is mainly received and evaluated by senses, a visual sense in particular. There might not be a standard or criterion, but overall mood and trend of the society act as decisive factors (Yuna Lee, 2007). Such trends react responsively to political, economic, cultural and artistic changes, then recreate itself in the modern society.

As the society advances, concept of beauty in pursuit of simplicity becomes very complex, standards to evaluate beauty have been more diverse, and aspects and characteristics of clothing culture appear to be very diverse as well (Yeongmi Lee, 1997). The importance of appearance also is magnified which is considered to be competitiveness in modern society so much so that various external elements are used to represent themselves such as clothing, hair and makeup as well as plastic surgery. Therefore, the total fashion which is combination of such external elements that magnifies the appearance is receiving much attention.

Overall harmony with clothing, hair style, accessary and makeup is very important in the total fashion. Clothing in the total fashion is of great importance since it plays a major role in expressing the wearer's personality and promoting personal charm. The hair style as a part of fashion is applied to develop one's own style, and it is a visible communication tool as a way to represent individuality so that it is becoming a required elements in daily life (H. Lee, 2003). Due to the trend of the total fashion, hair styles that enables self-dramatization are getting more and more attention.

Most people choose their clothing first and do the hair because clothing and hair style are interrelated to form an overall image. Necklines in particular has very close relation with hair style since it is physically closest to hair.

According to the previous researches related with this research, it is divided into the research about hair, the research about clothing details, the research about clothing composition and the research about the relationship between clothing and hair style. As for the research about hair, S. Kim (2008) analyzed the evolution of hair styles of early modern era and reproduced the hair styles, and N. Lee (2013) studied about the up style applying the formative characteristic of Rococo era hair styles. Kongsan Kim (2007) studied about the shape analysis of bob hair style by ear and the type of bob style according to face shape, and M. Lee (2007) investigated the preference for hair wave according to face shape based on hair wave type. As for the research about clothing details, Moon (1997) selected face shape of physical elements and neckline of clothing details as the factors of costume beauty and examined the visual effect of face shape and clothing details empirically through the wearing test according to the combination of face type and neckline type. And J. Lee (1989) studied about the change of collar of western costume from Middle Ages to modern times. As for the research about clothing composition, Ann (2008) studied about 
Kim Hyoju - Bae Soojeong / An Analysis on the Morphological Relationship of Hair Styles with Changes in Necklines and Collars

the collar pattern of tailored jacket and E. Kim (2012) studied about the retro creative characteristic of jacket design appeared in L'officiel magazine. As for the research about the relationship between clothing and hair style, $H$. Lee (2003) studied about the relationship between clothing style and hair style according to fashion images and S. Jung and Choi (2009) examined and analyzed the effect of the combination of neckline, hair style and earrings. But the researches about the specific formative relationship between the change of neckline and collar of clothing details and the change of hair style are inadequate until now. Thus, the objectives of present study are to analyze the hair styles changes from 16th to 19th centuries depending on the neckline and collar changes as well as the width and height of the necklines and to provide basic data of hair styles harmonious to necklines and collar in term of fashion coordination.

Literature and empirical studies are done concurrently. The literature studies is done focusing on domestic or foreign books, journals and thesis on the history of western costumes. For the picture data, paintings and portraits displayed in the art history or western costume history literatures from 16th to 19th centuries which show great details of necklines, collar and hair styles are referred (Arnold, 2005; Bazin, 2008; Bronwyn, 2000; Distel, 2003; Francois, 2004; Jane, 1996; Kwangwoo Kim, 2006; Richard, 2001; Robin, 2000) and analyzed through the secondary data. In order to ensure objectivity, 812 pictures are selected first by five experts who have Master's or higher degrees on Clothing and Textile major, prior to exclude 642 pictures which are considered to be improper for the analysis. Remaining pictures are mostly frontal views. 30 pictures are selected for each of 16th, 17th and 18th centuries. For 19th century, 20 pictures are selected for each styles of the Age of Empire Style, Age of Romantic Style, Age of Crinoline Style, and Age of Bustle \& S-curve Style for total of 170 pictures. With reference to the related papers (Ann, 2008; E. Kim, 2012) of composition area and focusing on selected pictures, the measurement method of neckline, collar and hair style was determined. Three evaluators are selected from Clothing and Textile majors for the objective results and average is computed from the evaluations. The trends and changes depending on each century and their relevances are analyzed.

The scope of study is limited to the relevances in shape of neckline, collar and hair style for each century from 16th to 19th. These time periods are selected since collars in apparel began to appear in earnest from 16th century (Sin, 2010) and there were distinct characteristics in fashion and hair style until 19th century whose data on elements of the clothing and hair styles are easily accessible.

\section{Hair Style Changes Depending on the Changes of Neckline and Collar for each Centuries}

From the 16th century to the 19th century, due to the frequent exchanges between countries, the costume of a country was mixed with other country's style or a few styles were mixed in one clothes. And it took time for one fashion to be propagated across Europe (Bae et al., 2008). Focusing on the most popular countries and costume at that times, I examined the change of neckline and collar. 


\section{16th Century: Age of Renaissance}

The word 'Renaissance' means to regenerate or revive, and is a transition era from medieval to modern times in which the literature, art and philosophy had seen great advancements (Han, Seo, \& Lee, 2001). Renaissance era had revived ancient Greek or Roman styles or even rose above them which influenced clothing styles. Clothing styles had evolved from covering human body in medieval to revealing so much so that there were styles that enlarged, exaggerated or distorted human body (Lehnert, 2005). In Renaissance era, beginning with Italy, Spain led the trend in the early era and its costume was propagated across Europe, and

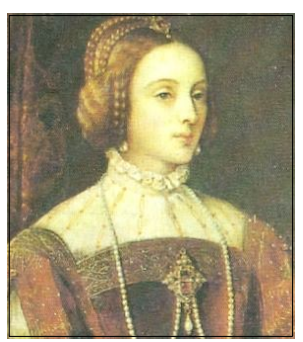

Figure 1.

Square Neckline, up Braiding

Hair Style, 1535

- A history of the costume in the west, p.223

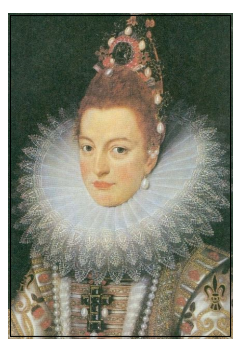

Figure 2. Reff Collar, up Hair Style, 1556-1633

- A history of costume in the west, p. 159

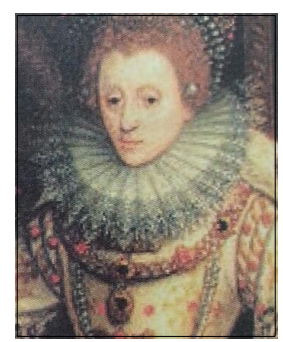

Figure 3. Reff Collar, up Hair Style, 1583

- Closet of queen Elizabeth 1, p.91 finally it was led by England in the late era (Bae et al., 2008). On the basis of this fact, this research examined the main costumes of Spain and England.

Ruff collars were used then to symbolize authority and dignity of noble class in different forms of circular, heart, butterfly or fan shapes.

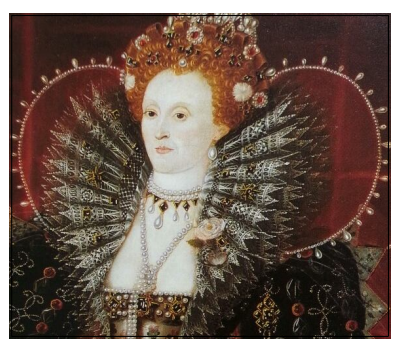

Figure 4.

Queen Elizabeth Collar, up Hair Style, 1599

- The art of dress, p.4
As collars had gotten larger, hair style had gotten smaller or tied up in a knot not to cover up the ruff collar with long hair. Main clothing trend of the Renaissance were ruff collar and neckline with additions of various hair Renaissance, long hair were in trend and later it was braided and tied up in a knot. Then, as the to cover up the ruff collar ( $H$. Jung, 2011). Figure 1, Figure 2, Figure 3, and Figure 4 . Th each display a square neckline with up braiding hair style, a ruff collar with up hair style and a

Queen elizabeth collar with up hair style, respectively.

\section{2. $17^{\text {th }}$ Century: Age of Baroque}

The word 'Baroque' is derived from a Spanish word, 'barruca', referring to an imperfect or 
Kim Hyoju - Bae Soojeong / An Analysis on the Morphological Relationship of Hair Styles with Changes in Necklines and Collars

rough pearl. Baroque style was dramatic and irregular based on passionate and sensual ethos (Kwon, 2006). In the early Baroque era, Holland led the trend and its costume was propagated across Europe, and finally it was led by France in the late era ( $\operatorname{Sin}, 2010)$. On the basis of this fact, this research examined the main costumes of Holland and France.

In early Age of Baroque, excessive splendor and exaggeration of $16^{\text {th }}$ century had gone, size of skirts had been reduced and mostly natural styles were preferred. New type of neckline, namely a bateau neckline, began to show up which were wide neckline almost to the shoulder points. The bateau neckline prevailed until the collar were in trend in early $17^{\text {th }}$ century, Fontange hair style was in trend. With the disappearance of the ruff collar around the middle of the era, a wave hair style with curls naturally falling to shoulder were in trend, sometimes even with ribbon accessories $(H$. Jung, 2011).

Representative necklines, collar and hair styles of the Age of Baroque are shown in Figure 5, Figure 6, Figure 7, Figure 8 and Figure 9. They each display a ruff collar with up hair style, a Vandyke collar with hulubulu hair style which is short wave hair style, a bateau neckline with short wave hair style and a square neckline with Fontange hair style, respectively.

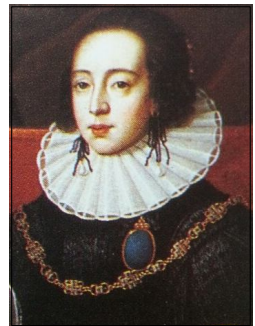

Figure 5

Reff Collar, up Hair Style, 1583

- The art of dress, p.67

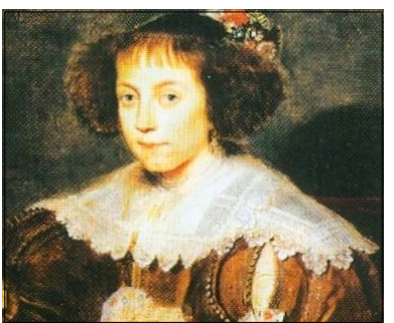

Figure 6.

Vandyke Collar, Hulubulu Hair Style, 1620-40

- A history of fashion. p.193

late Age of Baroque as well as a bustle Style (Ko, 2008). And the round shaped ruff collars of $17^{\text {th }}$ century had changed to a Polling band collar or Vandyke collar. These collars were popular with time difference according to the area of Europe. The hair style of the Baroque had of course changed influenced by new shapes of collar. When large ruff collar or whisk

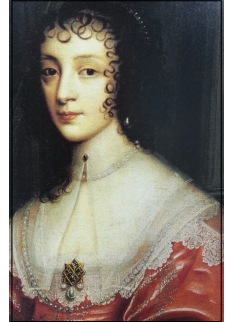

Figure 7. Vandyke Collar, Short Wave Hair Style, 1640

- The art of dress, p.193

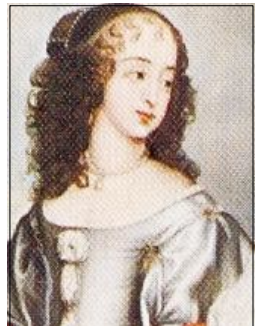

Figure 8. Bateau Neckline, Square Neckline, Short Wave Hair Fontange Hair Style, 1650

- A history of the -A history of costume in the fashion $\mathrm{p} .213$ west, p.268

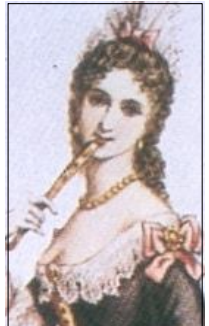

Figure 9. Style, $1670-90$ -A history of

\section{3. $18^{\text {th }}$ Century: Age of Rococo}

The word 'Rococo' is derived from a french word 'rocaille' meaning a pebble and another word 'coquille' meaning a clam shell (Cho \& Park, 2000). Age of Rococo had seen a transformation from masculine Baroque style into delicate and elegant feminine style. All the 
grandeur showing off had been gone and more humane emotions began to be channeled out with softness (Yuna Lee, 2007). This era is the time that the costume of France was in trend (Bae et al., 2008), and this research examined the main costumes of France.

Clothing of the Age of Rococo had deep necklines revealing the cleavage, extremely tight waist and wide skirt using hoops, influenced by the voluptuous and sensual salon culture. In its early era, clothing were extravagantly decorated with flowers or ribbons and displayed deep neckline, tiny waist and puffed skirt with use of décolleté, corset and panier hoop in its middle era (Jeong \& Bae, 2004). Toward the end of the era, Bustle silhouette was in trend with gathered back around the hip (Ji, 1999). As such, deep extreme height and decoration, thanks to Queen Marie Antoinette. Women of all class had imitated Queen's hair style, even to the extent of using a cushion filled with horse hair, steel wire, pomade or flour glue for an extremely large hair style (H. Jung, 2011).

Representative neckline, collar and hair styles are shown in Figure 10, Figure 11, Figure 12. Figure 13 and Figure 14. They each display a deep square neckline with Du Barry hair style, Pompadour hair style and pouf hair style, respectively.

\section{4. $19^{\text {th }}$ Century}

In $19^{\text {th }}$ century, modernization of western society took place, science, technology and industries

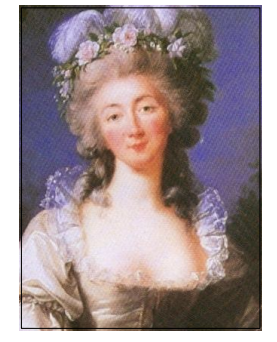

Figure 10. Square Neckline, Du Barry Hair Style, 1782

- A history of fashion, p.214

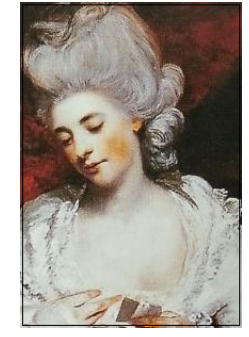

Figure 11. Square Neckline, Du Barry Hair Style, 1782

- Baroque and rococo, p.326

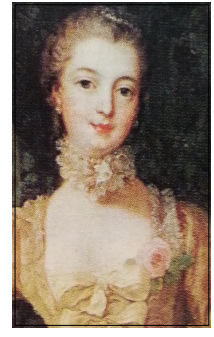

Figure 12. Square Neckline, Pompadour Hair Style, 1759

- A history of the - A history of the costume in the costume in the west, p.297

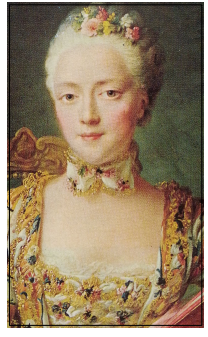

Figure 13. Square Neckline, Pompadour Hair Style, 1759 west, p.297

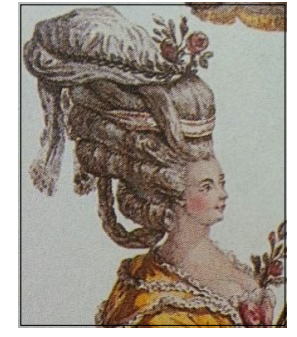

Figure 14.

Square Neckline, Pouf Hair Style, 1776 - A history of the costume in the west, p.293 square neckline with lace decoration was in trend in the Age of Rococo. In addition, the Age of Rococo had seen most gorgeous and emphasized form of hair styles such as Du Barry, Fontange and pouf hair styles. Around the end of $18^{\text {th }}$ century, hair style reached its began to develop with the industrial revolution and capitalism had begun to mature. Population transfer to urban area sped up and a middle class had formed between the investors and laborers. With an invention of sewing machine, that mass production of ready made costume flourished which promoted 
the standardization of garments. With the advancement of transportation and communication, garment industry became an international business. Thus the civil suit for the public people became the key of fashion (Bae et al., 2008) and the differences between main costume styles were almost disappeared so the people of all European countries wore the similar costumes.

The styles based on these situations generally categorized into the Age of Empire style, Age of Romantic style, Age of Crinoline style, Age of Bustle style and Age of S-curve style (Bae et al., 2008; Sin, 2010), so this research followed the division.

The characteristics of the empire style are the tubular silhouette emphasizing natural body lines, the off shoulder neckline emphasizing busts, the bateau neckline and the square neckline. ribbon sash on the high waist line emphasized busts and arms were almost bear with very short sleeves which were referred to the chemise gown. It usually was made with very thin fabric and body line was exposed for an erotic attractiveness. There also was the empire dress made with satin or velvet (Bae et al., 2008). Hair styles in the Age of Empire style was displaying wavy bangs in front with up style or natural style using a hairband. While hair style was on the simple side, hats were in trend such as a bonnet (Ko, 2008). Representative of the neckline, collar and hair styles in the age of the empire style is shown in Figure 15 displaying the off shoulder neckline with chignon hair style or combined short wave hair style.

The costumes in the Age of Romantic style tends to be on the romantic side with revival of abundant and colorful decorations influenced by Bourgeois. There were a lot of female costumes in pastel tone displaying $X$ silhouette with tightened waist and wide skirt. The bertha collar, bateau neckline or off shoulder neckline were trendy in this era (Heo, 1998). Hair styles in the Age of Romantic style were naturally long hair covering ears with hair parted in the middle and up style in the back. There were often silk flowers or ribbon decorating the hair (Bae et al., 2008). Representative neckline, collar and hair style are shown in Figure 16 displaying the bertha collar with chignon hair style and combination of short wave hair style.

The costumes in the Age of Crinoline style changed the shape of skirt with the use of Crinoline hoop to exaggerate and stiffen skirt. Size of the crinoline increased beginning in 1805 until it reached its largest around 1860. But a new bustle silhouette began to take over (Bae et al., 2008). Deep necklines such as the off shoulder neckline or bateau neckline were the trend $(H$. Jung, 2011). Hair style in the Age of crinoline style were kept rather simple despite the huge skirt in somewhat similar style as in the Age of Romantic style which was natural curls hanging down with hair parted in the middle and up style in the back. A chignon hair style began to show up which was an up style but with hair covering ears in a very feminie style. Twisted band with gold and silver thread, velvet ribbon or feather were a few of favorite hair decorations at the time (Sin, 2010). Representative neckline, collar and hair style is shown in Figure 17 displaying the off shoulder neckline with up braiding hair style.

The costumes in the Age of Bustle \& S-curve Style began to change in the direction of simple and practical. The bustle style with exaggerated hip which replaced the crinoline style added decorative train on the hip. The bustle style changed to the s-curve style influenced by the Art Nouveau around 1890. costumes in the Age of s-curve style were expressing human body 


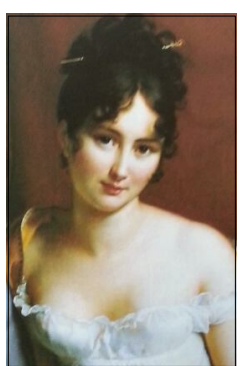

Figure 15.

Off Shoulder Neckline, Chignon \& Short Wave Hair Style, 1805

- L'art romantique, p. 44

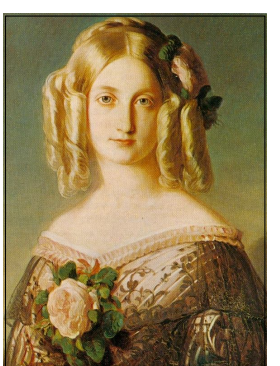

Figure 16.

Bertha Collar, Chignon \& Short

Wave Hair Style, 1846

- A history of the costume in the west, p.361

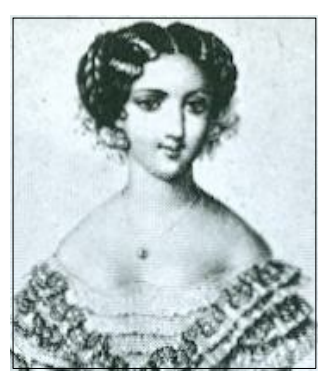

Figure 17

Off Shoulder Neckline, up Braiding Hair

Style, 1854

- A history of the costume in the west, p.377

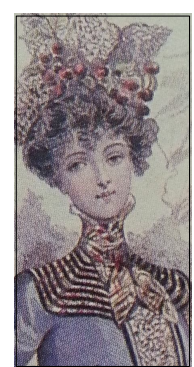

Figure 18.

Stand Collar, up Hair Style, 1900

- A history of

fashion, p.343

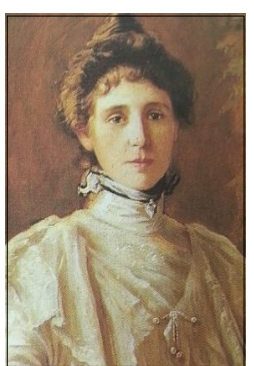

Figure 19.

Stand Collar, up Hair Style, 1902

- The art of dress, p.248 line naturally with emphasis on busts that the whole form looked like an $\mathrm{S}$ seen from the side and later emphasis on hip was added for maximum curved looks (Sin, 2010). In the Age of Bustle \& S-curve Style introduced the stand collar and natural wavy bangs and wigs for puffy effect of the Pompadour hair style (Jeon, 1994). Representative neckline, collar and hair style is shown in Figure 18, Figure 19 displaying the stand collar with up hair style.

\section{Relevance Analysis on the Shape of Hair Styles Depending on the Necklines and Collar Changes}

This chapter examines the relevance of widths and heights of hair style depending on the necklines and collar changes based on the hair style changes influenced by neckline and collar changes in each era in Chapter $\mathbf{I}$.

In order to analyze the relevance in terms of shapes, 170 pictures selected by the expert group are cut into same size to the end of both shoulders, to the top of head and to the line just below busts and printed with its height adjusted to make measurements. The base line for the measurement are horizontal line at the shoulders and vertical line at the center of the neck. If the neck is not visible or covered by collar, face is divided into three and a point $1 / 3$ below the chin is assumed to be the center of the neck. Figure 20, Figure 21 show the way of measurement. For an objective evaluation, three evaluators majoring in Clothing and Textile to compute the average values. The values are represented in a graph in 10 year increments. The average values in 10 year increments are shown in Table 1. The relevance of neckline, collar and hair style and the changes in trend for each century are analyzed in categories of width and height based on the Table 1 .

\section{Width}

Widths of neckline, collar and hair are measured in 0 to 10 with the distance between the center 
Kim Hyoju - Bae Soojeong / An Analysis on the Morphological Relationship of Hair Styles with Changes in Necklines and Collars

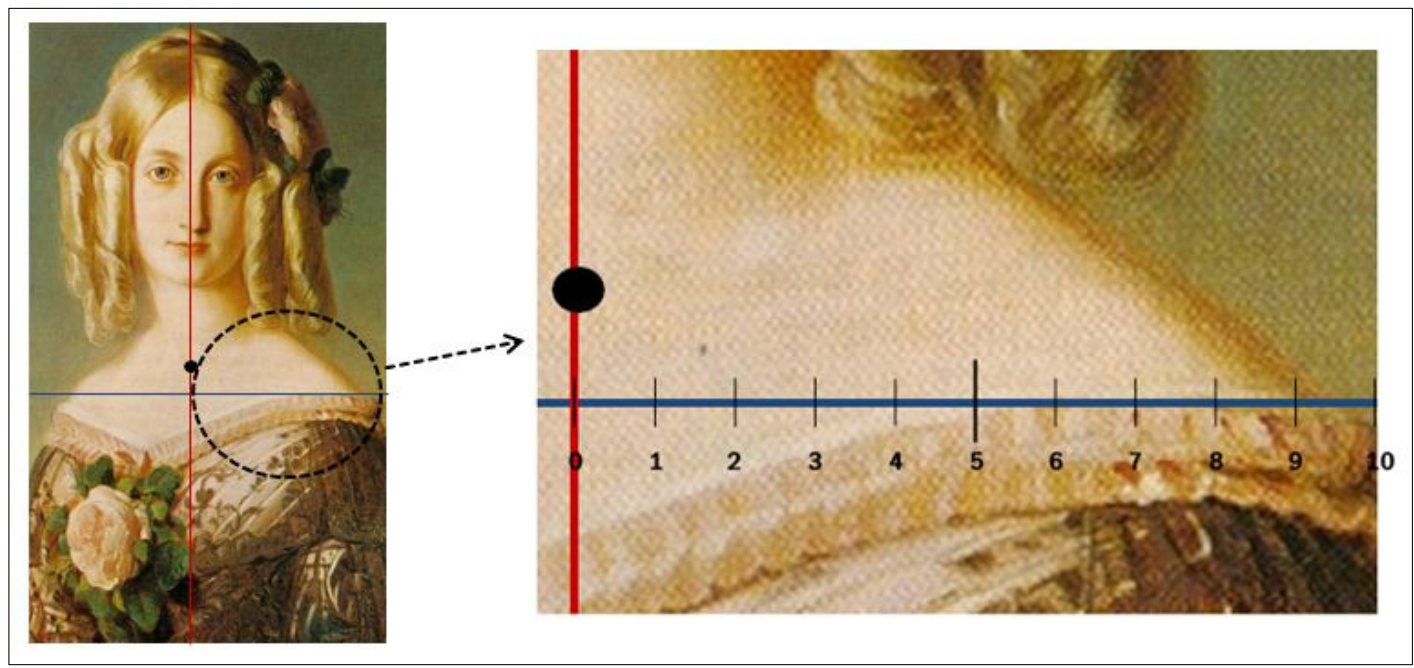

Figure 20. A Way of Measuring the Width Values

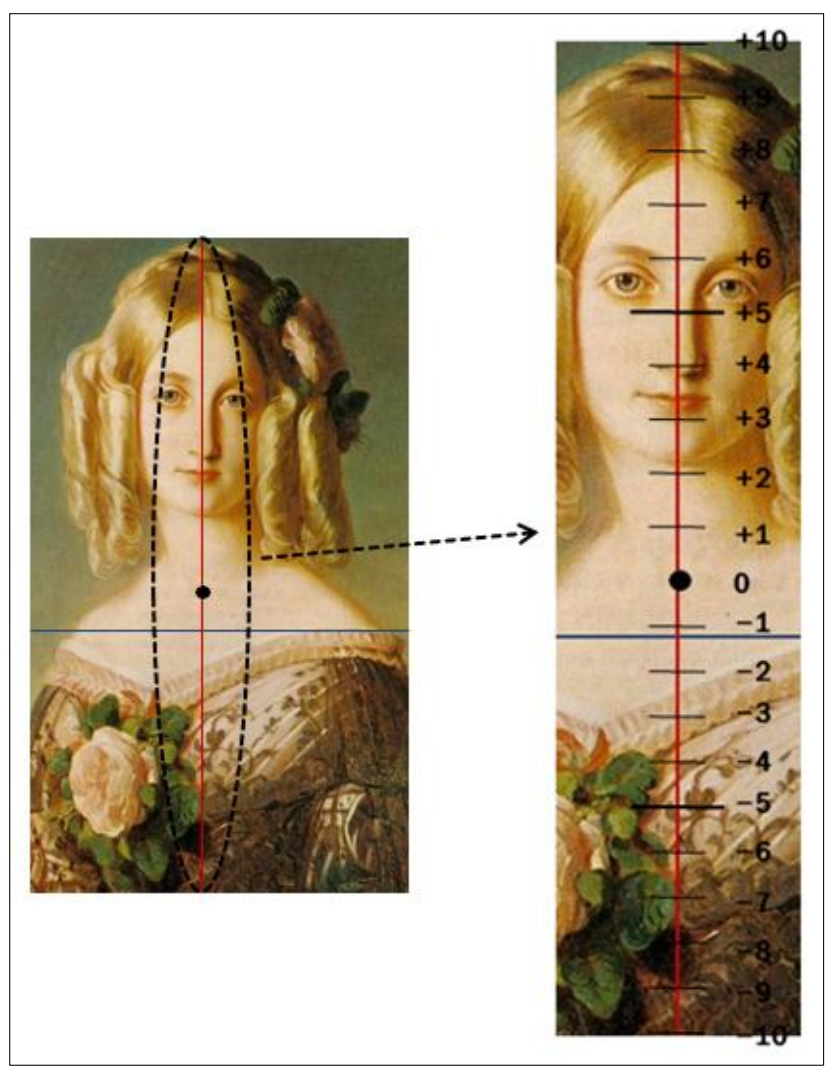

Figure 21. A Way of Measuring the Height Values 
of the neck and to the end of the shoulder equally divided into 10 . The followings are the results of the relevance analysis.

The collar on a costume began to show up in a form of simple neckline in the early of 16th century and became earnest collar around 1550 . The relevance of hair style influenced by such changes is that the width of hair style is inversely proportionate to the width of the neckline. In other words, wider the neckline width, narrower the hair style width or vise versa. However, the width of collar seemed to be highly related, on the contrary. Wider the collar, wider the hair style. Therefore, width of neckline and hair style is inversely proportionate but width of collar is proportionate to the width of hair style. This result is most influenced by wide ruff and Queen Elizabeth collars and wide hair style of 16 th century.

In early 17th century, there were various collars but between 1630 and 1650 began to show collar and neckline changes at the same time. The relevance of hair style due to this change is that the width of neckline is proportionate to the width of hair style. If neckline became wider or narrower, hair style became wider and narrower, respectively. And at the same time, the changes in collar width was proportionate to the changes in hair style width. If collar became wider or narrower, hair style became wider or narrower, respectively. The results tells that changes in neckline and collar width were proportionate to the hair style width in 17th century which seemed to be influenced by no more Ruff collars by this time and Vandyke collar were beginning to emerge, with it came the hulubulu hair style having a wide berth.

There were various neckline in 18th century but no collars. The relevance of hair style change is that the widths of neckline and hair style were inversely proportionate to each other. If neckline became wider or narrower, hair style became narrower and wider in inverse relations, respectively. The results are influenced most by the trends of that era which were wide square neckline with narrow Pompadour hair style, or narrow neckline with wide Du Barry hair style or pouf hair style.

The necklines in 19th century had been consistent from early on in the century till the end. Various collars began to appear around 1820 in earnest. The relevance of hair styles is that the changes in neckline and hair style widths are proportionate to each other. If neckline became wider or narrow, then hair style became wider or narrower, respectively. Same results with the changes in width of collar. If collar became wider or narrower, then hair style became wider or narrower, respectively. This results are similar to the results of 17th century which was influenced by the Empire style of narrow square neckline with narrow chignon hair style in combination with another narrow short wave hair style and in Romantic style of wide bertha collar with wide chignon hair style in combination with another wide short wave hair style. The result seemed to be influenced most by the Age of Crinoline style, wide off shoulder neckline was accompanied by wide up braiding hair style while in the Age of Bustle \& S-curve style, narrow stand collar was accompanied by narrow up hair style.

\section{Height}

The neckline, collar and hair style heights are measured. The distance from the center of the neck to the top of head is divided into 10 for a positive measurement and the distance from the 
center of the neck to the line just below the busts is divided into 10 for a negative measurement. The negative measurement means the hair is hanging down below the shoulder line. The relevance analysis of the hair style height are as the following.

There were various necklines in early $16^{\text {th }}$ century and collars began to emerge around 1550. The relevance of the hair style due to the change is that necklines were generally low cut as opposed to tall hair styles. If neckline became high or low, then hair style became low or tall, respectively. But the change in collar height were proportionate to the height of hair style. If collar became tall or low, then hair style became tall or low, respectively. The result is similar to the result of changes in hair style width due to the changes of neckline and collar widths of $16^{\text {th }}$ century that the height changes in neckline and hair style is inversely proportionate but the height changes in collar and hair style is proportionate tall up hair style not to cover the ruff collar.

In early $17^{\text {th }}$ century, there were various collars but between 1630 and 1650, neckline began to emerge. The relevance of the hair style change is that the hair style height change is proportionate to the neckline height change. If neckline became high or low, then hair style height became tall or low, respectively. And in much the same way, the hair style height change is proportionate to the collar height change. If collar became low, then hair style became also low. The result is similar to the result of hair style width changes in $17^{\text {th }}$ century due to the changes in neckline and collar widths. which seemed to be influenced by no more Ruff collars by this time and Vandyke collar were beginning to emerge, with it came the long hair style.
There were various neckline in $18^{\text {th }}$ century but no collars. The relevance of hair style change is that the hair style height change depending on the change of neckline height was proportionate to each other, until the 1750 according to the graph, however, the relevance is inversely proportionate from 1760 to 1790 . In other words, if neckline became high or low, then hair style became tall or low, respectively, until 1750 but if neckline became high or low, then hair style became low or tall in inverse relations from 1760 to 1790 . This result is similar to the result of changes in neckline and hair style widths in $18^{\text {th }}$ century. The result seemed to be influenced by new fashion and hair style of $19^{\text {th }}$ century and believed to be advance notice of emerging Empire style.

In $19^{\text {th }}$ century, there were necklines until 1820 but collars emerged in earnest beginning 1820 . The relevance of hair style due to this change is that the neckline height change was inversely proportionate to the hair style height change. If neckline became high or low, then hair style became tall or low, respectively. Similarly, collar height change was inversely proportionate to the hair style height change. If collar became high or low, then hair style became low or tall, respectively. This results is different from the result of the hair style width change in $19^{\text {th }}$ century and different from the generally proportionate results of other centuries as well. This result seemed to be influenced mostly by the low square neckline with combined hair style of tall chignon hair style and short wave hair style in the Age of Empire style, and the low bertha collar with combined hair style of tall chignon hair style and short wave hair style in the Age of Romantic style; When the low off shoulder neckline emerged in the Age of Crinoline style, hair style in trend was the tall up 
Journal of Fashion Business Vol.18, No.3

Table 1. Average Values for 10 Year Intervals of Width and Height

\begin{tabular}{|c|c|c|c|c|c|c|}
\hline & \multicolumn{3}{|c|}{ Width } & \multicolumn{3}{|c|}{ Height } \\
\hline & Neckline & Collar & Hair Style & Neckline & Collar & Hair style \\
\hline 1500 & 7 & & 1 & -2 & & -10 \\
\hline 1510 & 7 & & 2 & -3 & & -10 \\
\hline 1520 & 8 & & 1 & -4 & & 5 \\
\hline 1530 & 9 & & 1 & -4 & & 6 \\
\hline 1540 & 8 & & 3 & -3 & & 3 \\
\hline 1550 & 7 & 4 & 1 & -5 & 7 & 10 \\
\hline 1560 & 7 & 8 & 3 & -4 & 5 & 6 \\
\hline 1570 & 10 & 4 & 2 & -3 & 6 & 9 \\
\hline 1580 & 7 & 8 & 3 & -4 & 8 & 9 \\
\hline 1590 & 7 & 10 & 4 & -6 & 9 & 10 \\
\hline 1600 & & 10 & 3 & & 9 & 10 \\
\hline 1610 & & 9 & 3 & & 8 & 9 \\
\hline 1620 & & 9 & 2 & & 6 & 7 \\
\hline 1630 & 5 & 10 & 3 & -4 & 3 & -1 \\
\hline 1640 & 9 & 9 & 3 & -5 & -8 & -2 \\
\hline 1650 & 8 & 10 & 4 & -4 & -5 & -2 \\
\hline 1660 & 7 & & 2 & -6 & & -2 \\
\hline 1670 & 10 & & 3 & -8 & & -2 \\
\hline 1680 & 3 & & 2 & -4 & & 1 \\
\hline 1690 & 8 & & 3 & -5 & & 0 \\
\hline 1700 & 8 & & 2 & -7 & & 1 \\
\hline 1710 & 7 & & 1 & -6 & & 2 \\
\hline 1720 & 7 & & 1 & -5 & & 4 \\
\hline 1730 & 6 & & 2 & -6 & & 3 \\
\hline 1740 & 9 & & 1 & -7 & & 1 \\
\hline 1750 & 6 & & 2 & -6 & & 4 \\
\hline 1760 & 8 & & 1 & -5 & & 1 \\
\hline 1770 & 6 & & 3 & -5 & & -4 \\
\hline 1780 & 5 & & 3 & -6 & & -2 \\
\hline 1790 & 5 & & 4 & -4 & & -3 \\
\hline 1800 & 8 & & 2 & -5 & & 3 \\
\hline 1810 & 7 & & 1 & -6 & & 8 \\
\hline 1820 & 7 & 10 & 2 & -4 & -6 & 5 \\
\hline 1830 & 9 & 9 & 3 & -3 & -4 & 5 \\
\hline 1840 & 10 & 10 & 4 & -4 & -5 & 4 \\
\hline 1850 & 10 & 5 & 3 & -5 & 2 & 3 \\
\hline 1860 & 7 & 3 & 2 & -4 & 2 & 2 \\
\hline 1870 & 5 & 4 & 2 & -6 & 3 & 4 \\
\hline 1880 & 6 & 3 & 1 & -8 & 3 & 8 \\
\hline 1890 & 7 & 3 & 2 & -7 & 4 & 8 \\
\hline 1900 & 5 & 5 & 3 & -6 & 4 & 10 \\
\hline 1910 & 6 & 2 & 2 & 5 & 3 & 8 \\
\hline
\end{tabular}




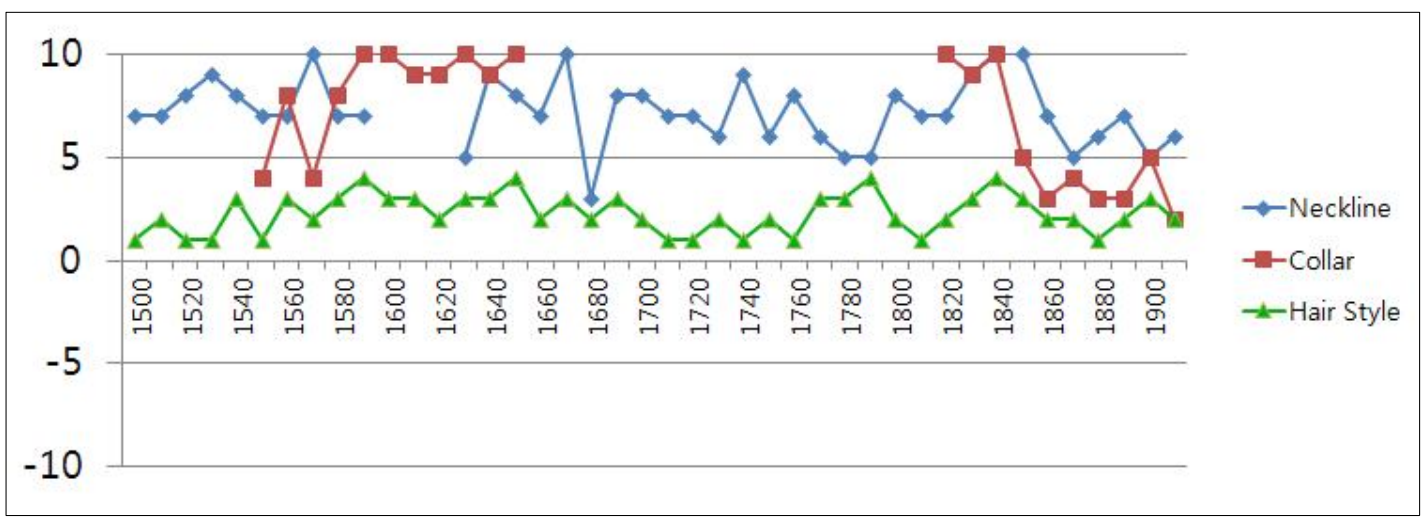

Figure 22. Correlation of Hair Style Width Depending on the Changes in Neckline and Collar Widths from $16^{\text {th }}$ Century to $19^{\text {th }}$ Century

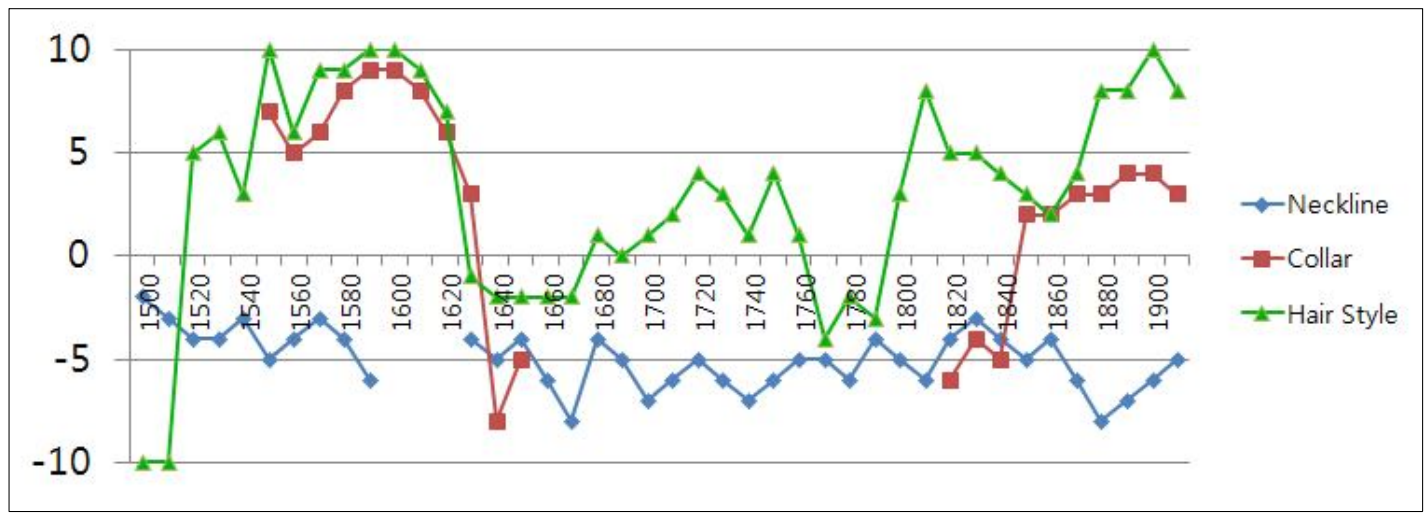

Figure 23. Correlation of Hair Style Height Depending on the Changes in Neckline and Collar Heights from $16^{\text {th }}$ Century to $19^{\text {th }}$ Century

braiding hair style and when the low stand collar was in trend in the Age of Bustle \& S-curve style, tall up hair style was in trend. This appears to be related to the historical background of emergence of various unique fashion outside of mimicking the fashion of the upper class influenced by the Enlightenment and new wealth due to industrial revolution. People were out of similar outfits and into diverse fashion reflecting their personality. Moreover, fashion changes very fast within the short period of 20 to 30 years, thus the results. Fast fashion change then was some sort of forecasting to diverse fashion on $20^{\text {th }}$ century.

Based on the analysis up to this point, the relevance in shape of hair style depending on the changes in neckline and collar can be analyzed in categories of width and height.

First, the relevance in width: The neckline and hair style widths were inversely proportionate in $16^{\text {th }}$ century as shown in Figure 22 while collar and hair style widths were proportionate to each 
other. The neckline and collar widths were proportionate to each other in $17^{\text {th }}$ century. There were no collar but just necklines in $18^{\text {th }}$ century, in which the neckline and hair style width were inversely proportionate. The result of hair style change depending on neckline and collar widths in $19^{\text {th }}$ century were similar to result of $17^{\text {th }}$ century in which the neckline and collar widths are proportionate to hair style width. In addition, the degree of change in hair style width was not as large as the degree of change in neckline and collar width changes.

Next, the relevance in height: The neckline and hair style height changes were inversely proportionate in $16^{\text {th }}$ century as shown in Figure 23 while the collar and hair style height changes were proportionate to each other. The neckline and collar height changes were proportionate to the hair style height changes in $17^{\text {th }}$ century. There were no collar but just necklines in $18^{\text {th }}$ century, in which the neckline and hair style height changes were inversely proportionate. In $19^{\text {th }}$ century, the hair style height changes were inversely proportionate to both neckline and collar height changes, unlike the results for other centuries. In addition, the degree of change in hair style and collar heights were larger while the degree of neckline height change was relatively small which demonstrates there were greater changes in the height changes than in the width changes. It seemed to be influenced by various collar and hair style which had gone through greater changes in terms of height.

\section{Conclusion}

To be in step with the fact that one's appearance is considered to be competitiveness in modern society, interests in total fashion is growing fast in terms of external elements such as clothing, hair style and makeup as well as plastic surgery in order to highlight appearance. Most people choose clothing that best represent them, then hair style that goes with it. As such, clothing and hair style made a whole image though their interrelations and neckline and collar in particular are closely related to hair style due their approximation to hair.

Present study has examined historical changes of neckline, collar and hair style from $16^{\text {th }}$ century to $19^{\text {th }}$ century in order to analyze the relevance of shape in hair style changes depending on neckline and collar changes. Widths and heights of neckline, collar and hair style were measured from the selected pictures representing each centuries dominant fashion, and the relevance in shape of neckline, collar and hair style were analyzed based on the measurements.

In order to the analysis, 170 pictures selected by expert group were cut in same sizes between the shoulders and from top of hair to the line just below the chest and measurement were made. For an objective evaluation, three evaluators majoring in Clothing and Textiles had made the measurements and their average values were calculated. The values were entered into a graph in 10 year intervals to see the trend in change and their relevance in widths and heights. The results are as follows.

In $16^{\text {th }}$ century, both width and height changes in neckline and hair style were inversely proportionate while both width and height changes in collar and hair style were proportionate. This result seemed to be influenced by the emergence of ruff collar and Queen Elizabeth collar and as their width increased, hair style width also increased as well as the trend of up hair style not to cover the 
Kim Hyoju - Bae Soojeong / An Analysis on the Morphological Relationship of Hair Styles with Changes in Necklines and Collars

collar.

In $17^{\text {th }}$ century, the hair style width and height changes were proportionate to the neckline and collar width and height changes. Unlike the results of $16^{\text {th }}$ century, ruff collar were gone in $17^{\text {th }}$ century and wide and flat Vandyke collars were in trend instead. With the new collar style came very wide hulubulu hair style, and with the emergence of the Vandyke collar, long hair was in trend as well.

There were various neckline in $18^{\text {th }}$ century but no collars. Changes in neckline and hair style width and height were both inversely proportionate since wide neckline was matched with narrow Pompadour hair style while narrow neckline was matched with wide hair styles such as Du Barry hair style or pouf hair style in $18^{\text {th }}$ century. These results seemed to be under noticed for the transition into new fashion and hair style of $19^{\text {th }}$ century.

In $19^{\text {th }}$ century, the hair style width changes were proportionate to the neckline and collar width changes while the hair height changes were inversely proportionate to the neckline and collar height changes. This result seemed to be influenced by the narrow neckline matched with the combination of wide chignon hair style and short wave hair style in the Age of Empire style and the wide bertha collar was matched with the combination of wide chignon hair style and short wave hair style in the Age of Romantic style.

In the Age of Crinoline style, wide off shoulder neckline was matched with wide up braiding hair style. In the Age of Bustle \& S-curve style, narrow stand collar was matched with narrow up hair style. In the Age of Empire style, tall square neckline was matched with combination of tall chignon hair style and short wave hair style. In the Age of Romantic style, low bertha collar was matched with combination of tall chignon hair style and short wave hair style. In the Age of Crinoline style, low off shoulder neckline was matched with tall up braiding hair style. In the Age of Bustle \& S-curve style, low stand collar was matched with tall up hair style. This appears to be related to the historical background of emergence of various unique fashion outside of mimicking the fashion of the upper class influenced by the Enlightenment and new wealth due to industrial revolution. People were out of similar outfits and into diverse fashion reflecting their personality. Moreover, fashion changes very fast within the short period of 20 to 30 years, thus the results. Fast fashion change then was some sort of forecasting to diverse fashion on $20^{\text {th }}$ century.

Based on the above study and the relevance analysis in shapes of neckline, collar and hair styles, hair style had changed depending on the clothing elements such as neckline and collar, and the change were happening faster as fashion was diversified in modern times. In addition, the degree of hair style width change was not as great as the width changes of neckline or collar while the degree of hair style and collar height changes were huge compared to that of neckline. At the same time, degree of height change was greater than that of width which indicates that collar and hair style had changed more than the neckline in term of height.

For this research, among the clear illustrations of neckline, collar and hair style, the illustrations of front look were selected as far as possible. Especially in the 19th century, various styles have appeared so the number of selected illustration by century is different. But this result will be the basic data for creating the hair style matching a specific neckline and collar, and 
furthermore, the following researches about the formative relationship between head dress and accessory as well as neckline, collar and hair style and about different times are also needed.

\section{References}

Ann, H. (2008). A study on tailored collar pattern for jacket (Unpublished master's thesis). Konkuk University, Seoul, Korea.

Arnold, M. (2005). Henri de toulouse-lautrec. (M. Jeong, Trans.). Seoul: Maroniebooks.

Bae, S., Hyun, S., Bak, J., Oh, H., Jung, K., Kim, E... \& Lee, k. (2008). Contemporary fashion \& historic costume in the west. Seoul: Soohaksa.

Bae, S. (2011). Closet of queen Elizabeth 1. Seoul: Soohaksa.

Bazin, G. (1998). Baroque and rococo. (M. Kim, Trans.). Seoul: Sigongsa.

Bronwyn C. (2000). The complete history of costume \& fashion. NY: Checkmark Books.

Cho, O., \& Park, H. (2000). 복식과 문화 [Costume and culture]. Seoul: Changwon University Press.

Distel, A. (2003). Renoir, "ll faut embellir". (E. Song, Trans.). Seoul: Sigongsa.

Francois B. (2004). A history of costume in the west. LD: Thames \& Hudson.

Han, S., Seo, O., \& Lee, M. (2001). A history of fashion. Seoul: Soohaksa.

Heo, K. (1998). History of fashion. Seoul: Ism.

Jane A. (1996). The art of dress. NY: Harry N Abrams.

Jeon, S. (1994). A study on change of western woman's hair style (Unpublished master's thesis). Ewha Womans University, Seoul, Korea.

Jeong, K., \& Bae, S. (2004). A study on the hoop applied on contemporary fashion. Journal of Fashion Business, 8(2), 126-140.

$\mathrm{Ji}$, J. (1999). The study on trends of costume, hair style, make up in 18th century Rococo fashion (Unpublished master's thesis). Taegu University, Taegu, Korea.

Jung, H. (2011). 서양복식문화사 [A history costume in the west]. Paju: Kyomunsa. (Original work published 1981). historic costume in the west

Jung, S., \& Choi, S. (2009). The effect of coordination of earring, neckline, and hair style on image. Korean Journal of Human Ecology, 18(2), 535-545.

Kim, E. (2012). Creative characteristic study of the jacket design appeared in L'officiel magazine (Unpublished doctor's thesis). Kyunghee University, Seoul, Korea.

Kim, K. [Kongsan]. (2007). A study on the analysis of form and classification in bob hair styles (Unpublished master's thesis). Yongin University, Yongin, Korea.

Kim, K. [Kwangwoo]. (2006). French art 500 years. Seoul: Misulmunhwa.

Kim, S. (2008). The history of changes in hair styles in modern age and reproduction of works. Journal of the Korean Beauty Art Society, 2(2), 165-172.

Ko, A. (2008). A history of fashion. Paju: Kyomunsa.

Kwon, K. (2006). The study for comparing makeup and ideal beauty on the Renaissance and the Baroque portraits. Journal of Fashion Business, 10(4), 78-94.

Lee, H. (2003). The correlation between clothing style and hair style related to fashion image (Unpublished master's thesis). Kyungsung University, Busan, Korea.

Lee, J. (1989). A study on the change of collar style of western clothing. Journal of Human 
Kim Hyoju - Bae Soojeong / An Analysis on the Morphological Relationship of Hair Styles with Changes in Necklines and Collars

Economics, 5, 67-80.

Lee, M. (2007). A study of degrees of preference for hair waves according to face shapes (Unpublished master's thesis). Hansung University, Seoul, Korea.

Lee, N. (2013). A study on the modern up-style design (Unpublished master's thesis). Hansung University, Seoul, Korea.

Lee, Y. [Yeongmi]. (1997). Effect of hair style neckline combinations on the perception of face image and type (Unpublished master's thesis). Hanyang Womans University, Seoul, Korea.

Lee, Y. [Yuna]. (2007). A study on beauty culture about Rococo of the 18th century (Unpublished master's thesis). Sunghin Womans University, Seoul, Korea.

Lehnert, G. (2005). Fashion-interesting fashion history at a glance. (S. Park, Trans.). Seoul: Yekyong.

Legrand, G. (2007). L'art romantique. (H. Park, Trans.). Seoul: Trees of the think.
Moon, N. (1997). The effects of face types and a detail of clothes on visual evaluation: Focused on womens' necklines (Unpublished doctoral dissertation). Chonnam National University, Gwangju, Korea.

Richard, C. (2001). Fashion in hair. LD: Peter O Wen.

Robin, B. (2000). The history of hair. LD: Philip Wilson.

Sin, S. (2010). A history costume in the west. Seoul: Soohaksa. (Original work published 2006).

Yun, S., \& Bae, S. (2002). A study of ruff collar reflected on the late 20th century fashion. Journal of Fashion Business, 6(4), 32-45.

Received (June 30, 2014)

Revised (July 10, 2014)

Accepted (July 18, 2014) 